\title{
DISTRIBUIÇÃO RADICULAR, ESTADO NUTRICIONAL E PRODUÇÃO DE COLMOS E DE AÇÚCAR EM SOQUEIRAS DE DOIS CULTIVARES DE CANA-DE-AÇÚCAR EM SOLOS DISTINTOS ${ }^{(1)}$
}

\author{
Mirian Cristina Gomes Costa ${ }^{(2)}$, Jairo Antônio Mazza ${ }^{(3)}$, Godofredo \\ Cesar Vitti $^{(4)}$ \& Lucio André de Castro Jorge ${ }^{(5)}$
}

\begin{abstract}
RESUMO
O presente trabalho de pesquisa foi elaborado com o objetivo de comprovar a hipótese de que o cultivar de cana-de-açúcar RB83-5486, comparado ao RB835089 , apresenta melhor distribuição radicular mediante cultivo em solo com menor teor de argila. $O$ estudo foi realizado a partir de dois experimentos de campo desenvolvidos no município de Porto Feliz, SP. Os solos foram classificados como Nitossolo Vermelho eutroférrico latossólico (NV) e Latossolo Vermelho-Amarelo distrófico psamítico (LVA). No período entre a terceira e a quinta soca (2002 a 2004), os cultivares de cana-de-açúcar RB83-5486 e RB83-5089 foram avaliados a partir de estudos de atributos químicos e físicos do solo, do estado nutricional da cultura, da distribuição de raízes no perfil do solo e da produtividade e qualidade tecnológica da cana-de-açúcar. A distribuição de raízes foi avaliada utilizando-se o método da trincheira ou parede do perfil. Os resultados indicaram diferença na concentração de hidrogênio dos solos relacionada com a atividade dos cultivares na absorção de nutrientes. O teor foliar de potássio e enxofre foi maior para o cultivar RB83-5486. No LVA, ambos os cultivares apresentaram maior quantidade de raízes concentrando-se até os $18 \mathrm{~cm}$ de distância a partir das linhas de cana e até os $54 \mathrm{~cm}$ de profundidade. No NV, o cultivar RB83-5486 apresentou maior quantidade de raízes concentrando-se até $23 \mathrm{~cm}$ de distância a partir das linhas de
\end{abstract}

\footnotetext{
${ }^{(1)}$ Parte da Tese de Doutorado do primeiro autor, financiada pela FAPESP e CAPES. Recebido para publicação em 27 agosto de 2005 e aprovado em julho de 2007.

(2) Pesquisadora da Embrapa Roraima. CEP 69301-970 Boa Vista (RR). Email: mirian@cpafrr.embrapa.br

${ }^{(3)}$ Professor do Departamento de Solos e Nutrição de Plantas, Escola Superior de Agricultura Luiz de Queiroz - ESALQ/USP. Escola Superior de Agricultura "Luiz de Queiroz" - ESALQ/USP. Av. Pádua Dias 11, Caixa Postal 09, CEP 13418-900 Piracicaba (SP). Email: jamazza@esalq.usp.br.

(4) Professor Titular do Departamento de Solos e Nutrição de Plantas, ESALQ/USP. Email: gcvitti@esalq.usp.br

${ }^{(5)}$ Pesquisador da Embrapa Instrumentação Agropecuária, CEP 1350-970, São Carlos (SP). Email: lucio@cnpdia.embrapa.br
} 
cana e até os 46 cm de profundidade. Já o cultivar RB83-5089 mostrou distribuição do sistema radicular mais uniforme no NV. A produção de colmos foi maior no cultivar RB83-5089; contudo, a produção de açúcar foi maior em RB83-5486.

Termos de indexação: cana, raízes, sistema radicular, método da trincheira, Saccharum officinarum $\mathbf{L}$.

\title{
SUMMARY: ROOT DISTRIBUTION, PLANT NUTRITIONAL STATUS, AND STALK AND SUGAR YIELD IN TWO GENOTYPES OF SUGARCANE IN DISTINCT SOILS
}

\begin{abstract}
Two field experiments were carried out in Porto Feliz, SP, Brazil, to test the hypothesis that in soils with low clay content, sugarcane genotype RB83 5486 has a better root system distribution than genotype RB83-5089. The two soils used were classified as Typic Kandiudalf and Typic Hapludox. Between the third and fifth ratoon (2002 to 2004), the development of the sugarcane genotypes RB83-5486 and RB83-5089 was evaluated by determining the chemical and physical soil attributes, crop nutritional status, root distribution in the soil profile, and stalk and sugar yield. Root distribution in the soil profile was evaluated by the trench method. Results show differences in hydrogen ion concentrations in both soils. These differences can be related to differences in the nutrient uptake of the studied genotypes. Potassium and sulphur contents in sugarcane leaves were higher in genotype RB83-5486. In the Typic Hapludox most part of the roots of both genotypes were concentrated at 0 to $18 \mathrm{~cm}$ from the cane rows and in the upper $54 \mathrm{~cm}$. In the Typic Kandiudalf, most part of the roots of genotype $R B 835486$ was concentrated at a distance of 0 to $23 \mathrm{~cm}$ from the sugarcane rows and in the upper $46 \mathrm{~cm}$. The root system of genotype RB83-5089 was more evenly distributed in the Typic Kandiudalf. Stalk yield was higher for genotype RB83 5089, while sugar yield was higher for genotype RB83-5486.
\end{abstract}

Index terms: sugar cane, roots, root system, trench method, Saccharum officinarum $L$.

\section{INTRODUÇÃO}

A possibilidade de existirem diferenças entre genótipos de cana-de-açúcar, relacionadas ao sistema radicular, deve ser mais bem explorada na busca de cultivares que apresentem maior eficiência na absorção de água e nutrientes do solo.

Dias (1997) estudou a interação de seis cultivares de cana-de-açúcar em diferentes ambientes (solo x clima) e constatou que, em solo eutrófico, com variação textural no perfil e com regime hídrico não limitante ao desenvolvimento das plantas, todos os cultivares estudados expressaram plenamente o potencial genético. Entretanto, em solo álico, sem variação textural no perfil e com elevada drenagem que conduziu a regime hídrico limitante, os cultivares estiveram muito aquém de seu potencial genético de produtividade.

O plantio dos cultivares RB85-5113, RB85-5536, RB72-454, RB85-5453, RB83-5019, RB83-5486, RB845257, SP73-1011 e SP80-1842 nos solos Planossolo e Podzólico Vermelho-Amarelo foi avaliado por Maule et al. (2001). Os autores constataram que os cultivares RB85-5113, RB85-5453, SP79-1011, RB72-454 e SP80-1842 não apresentaram desenvolvimento diferenciado nos dois solos, provavelmente por possuírem maior adaptabilidade. Entretanto, os cultivares RB85-5536, RB83-5019, RB83-5486 e RB845257 expressaram desenvolvimento variado em função da interação com o ambiente, mostrando diferentes respostas de produtividade agrícola.

Quanto à distribuição no perfil de solo, Avilan et al. (1977) mencionam que os fatores que mais afetam o sistema radicular da cana-de-açúcar são o nível do lençol freático, o impedimento mecânico e as características químicas do solo. Avilan (1978) verificou que, na profundidade entre 25 e $50 \mathrm{~cm}$, a baixa macroporosidade restringiu a penetração radicular da cana-de-açúcar.

A densidade do solo maior que $1,02 \mathrm{~g} \mathrm{~cm}^{-3}$ causou deformação ou restrições na distribuição de raízes de cana-de-açúcar; densidade de $1,25 \mathrm{~g} \mathrm{~cm}^{-3}$ provocou danos nas radicelas; densidade de $1,36 \mathrm{~g} \mathrm{~cm}^{-3}$ reduziu a quantidade de raízes e causou distorção nas radicelas; e densidade maior ou igual a $1,46 \mathrm{~g} \mathrm{~cm}^{-3}$ comprometeu a penetração das raízes no solo (Humbert, 1974).

Avilan (1978) verificou que a maior concentração radicular ao redor das soqueiras está na distância de 0 a $35 \mathrm{~cm}$, enquanto a menor concentração radicular está na distância de 35 a $70 \mathrm{~cm}$ da touceira. Esse 
autor constatou que a maior concentração de raízes está na profundidade de 30 a $50 \mathrm{~cm}$. Fernandes (1985) menciona que 60 a $70 \%$ das raízes de cana-de-açúcar estão nos primeiros $40 \mathrm{~cm}$ de profundidade na fase inicial de desenvolvimento da cultura. Já a maior concentração de raízes na horizontal está a 30-40 cm das linhas de cana. Estudando o crescimento de raízes de cana colhida com queima e sem queima, Alvarez et al. (2000) verificaram que $75 \%$ das raízes de cana colhida sem queima situaram-se nos primeiros $40 \mathrm{~cm}$ de profundidade do solo no primeiro ano de análise e $70 \%$ delas concentraram-se nessa profundidade na avaliação de segundo ano. Já para cana colhida queimada, os valores foram de $72 \%$ de raízes nos primeiros $40 \mathrm{~cm}$ no primeiro ano e de $68 \%$ no segundo ano.

Gomes (2003) demonstrou que a média de produtividade de três cortes do cultivar RB83-5089 plantado em solo com maior teor de argila foi aproximadamente 20 toneladas maior que a encontrada para o RB83-5486. Entretanto, quando plantado em solo de textura arenosa na mesma época, o cultivar RB83-5089 apresentou média de três cortes 10 toneladas menor que a do RB83-5486. Com base nessa informação, foi elaborado o presente trabalho de pesquisa com o objetivo de comprovar a hipótese de que o cultivar RB83-5486, comparado ao RB83-5089, apresenta melhor produtividade em solo com menor teor de argila, por possuir melhor distribuição do sistema radicular no perfil do solo.

\section{MATERIAL E MÉTODOS}

O estudo foi realizado a partir de dois experimentos de competição varietal, que foram instalados em agosto de 1998. No período entre a terceira e a quinta soca (2002 a 2004), os cultivares de cana-de-açúcar RB835486 e RB83-5089 foram avaliados a partir de estudos de atributos químicos e físicos do solo, do estado nutricional da cultura, da distribuição de raízes no perfil do solo e da produtividade e qualidade tecnológica da cana-de-açúcar.

As áreas experimentais situaram-se no município de Porto Feliz, SP (latitude S $23^{\circ} 13^{\prime} 02$ " e longitude O $47^{\circ} 31^{\prime} 35$ ”). A altitude predominante na região é de 554 m, e o clima é Cwa (sistema de Köppen). Os solos das áreas experimentais foram classificados como Latossolo Vermelho-Amarelo distrófico psamítico (LVA) e Nitossolo Vermelho eutroférrico latossólico (NV) (Embrapa, 1999). No quadro 1 são apresentados os atributos de amostras coletadas antes da instalação dos experimentos. No quadro 2 encontram-se os resultados da análise textural.

Até a safra 2001/2002, as áreas experimentais receberam $150 \mathrm{~m}^{3} \mathrm{ha}^{-1}$ de vinhaça, fornecendo, de acordo com as análises químicas do resíduo, 126, 13 e $645 \mathrm{~kg} \mathrm{ha}{ }^{-1}$ de $\mathrm{N}, \mathrm{P}_{2} \mathrm{O}_{5}$ e $\mathrm{K}_{2} \mathrm{O}$, respectivamente. A partir da safra 2002/2003, no cultivo das soqueiras, ambas as áreas experimentais receberam aplicações de $500 \mathrm{~kg} \mathrm{ha}^{-1}$ da fórmula 18-00-27, fornecendo $90 \mathrm{e}$ $135 \mathrm{~kg} \mathrm{ha}^{-1}$ de $\mathrm{N}$ e $\mathrm{K}_{2} \mathrm{O}$, respectivamente, visando produtividade aproximada de $100 \mathrm{t} \mathrm{ha}^{-1}$ de colmos.

O delineamento experimental para avaliação de atributos físicos do solo foi em parcelas subdivididas. No estudo dos atributos físicos foram considerados dois cultivares (RB83-5089 e RB83-5486), três profundidades no perfil (0-20, 20-40 e 40-100 cm) e três repetições. A distribuição de raízes no perfil foi avaliada com base no delineamento em parcelas subsubdivididas, com dois cultivares (RB83-5089 e RB83-5486), três distâncias horizontais a partir das

\section{Quadro 1. Atributos do solo em duas profundidades}

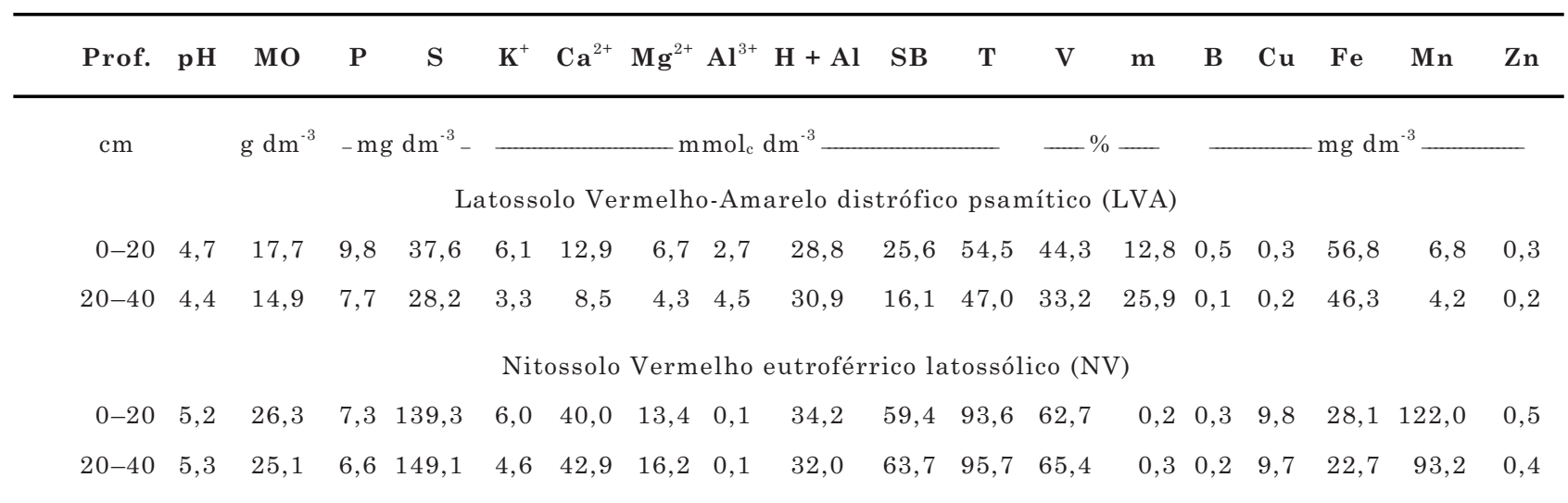

pH: $\mathrm{CaCl}_{2}$ 0,01 mol L-1 (Raij et al., 2001). MO: matéria orgânica, método colorimétrico (Raij et al., 2001). P: extração por resina trocadora de íons e determinação em fotómetro de chama (Raij et al., 2001). S: $\mathrm{NH}_{4} \mathrm{OAc} 0,5 \mathrm{~N}$ em HOAc 0,25 N (Vitti, 1988). K: extração por resina trocadora de íons e determinação em fotómetro de chama (Raij et al., 2001). Ca e Mg: extração por resina trocadora de íons e determinação por espectrometria de absorção atômica (Raij et al., 2001). H + Al: determinação por potenciometria em solução-tampão SMP (Raij et al., 2001). $\mathrm{Al}$ : $\mathrm{KCl} 1 \mathrm{~mol} \mathrm{~L}^{-1}$ (Raij et al., 2001). $\mathrm{B}$ : $\mathrm{BaCl}_{2} .2 \mathrm{H}_{2} \mathrm{O} 0,125 \%$ microondas (Abreu et al., 2001a). Cu, Fe, Mn, Zn: DTPA: TEA pH 7,3 (Abreu et al., 2001b). 
Quadro 2. Análise granulométrica de diferentes horizontes dos solos das áreas experimentais

\begin{tabular}{cccc}
\hline Horizonte & Areia & Argila & Silte \\
\hline cm & & & \\
Latossolo & & & \\
$0-30$ & 83 & 12 & \\
$31-75$ & 79 & 12 & 9 \\
$76-105$ & 79 & 15 & 6 \\
$106+$ & 81 & 15 & 4 \\
Nitossolo Vermolho eutroférrico latossólico (NV) & \\
$0-30$ & 40 & 51 & 9 \\
$31-65$ & 28 & 65 & 7 \\
$66-75$ & 30 & 62 & 8 \\
$76+$ & 23 & 62 & 15 \\
\hline
\end{tabular}

Método do densímetro (Gee \& Bauder, 1986).

linhas de cana $(0-18,18-36$ e $36-54 \mathrm{~cm}$ no LVA e $0-23,23-46$ e $46-69 \mathrm{~cm}$ no NV) e três repetições. Entretanto, no LVA foram consideradas quatro profundidades no perfil do solo $(0-18,18-36,36-54$ e $54-72 \mathrm{~cm})$ e, no NV, somente três $(0-23,23-46$ e 46 $69 \mathrm{~cm})$.

Após colheita da safra 2001/2002, foi realizada amostragem de solo nas profundidades de $0-20 \mathrm{e}$ $20-40 \mathrm{~cm}$. A avaliação do estado nutricional foi feita para as safras 2002/2003 e 2003/2004. Na fase de máximo crescimento da cultura (aproximadamente quatro meses após início da brotação das soqueiras) coletaram-se amostras da folha +3 , conforme o sistema Kuijper, segundo Gallo (1962). As amostras foram secas em estufa e moídas, para posterior determinação de macro e micronutrientes (Malavolta et al., 1997).

Para avaliação da curva de retenção de água, macroporosidade e densidade do solo, coletaram-se 18 amostras indeformadas em cada experimento. As amostras foram coletadas em fase intermediária de desenvolvimento da cana-de-açúcar para a safra 2002/ 2003, em três perfis de solo, para os cultivares RB835486 e RB83-5089. A amostragem foi direcionada considerando a análise prévia do perfil de solo, na qual se verificaram diferentes condições de compactação na entrelinha da cultura nas profundidades de $0-20$, $20-40$ e $40-100 \mathrm{~cm}$.

As amostras foram coletadas em anéis metálicos ( $5 \mathrm{~cm}$ de diâmetro e $3 \mathrm{~cm}$ de altura). No laboratório, após saturação, as amostras foram pesadas, colocadas em mesa de tensão e submetidas às pressões de 0,01 ; 0,$04 ; 0,05 ; 0,06 ;$ e $0,1 \mathrm{~atm}$. Após pressão de 0,1 atm, as amostras foram colocadas em câmaras de pressão e submetidas às pressões de 0,$33 ; 0,7 ; 1,0 ; \mathrm{e} 15 \mathrm{~atm}$.
A determinação da resistência à penetração (RP) foi feita em cada uma das amostras indeformadas, com três repetições por amostra. Para medidas da RP foi utilizado penetrômetro desenvolvido no Laboratório de Física do Solo do Departamento de Solos e Nutrição de Plantas da ESALQ/USP.

Após medidas de RP, as amostras indeformadas foram pesadas e colocadas em estufa a $105^{\circ} \mathrm{C}$ durante $24 \mathrm{~h}$, para determinação da umidade gravimétrica $(\theta \mathrm{u})$ e densidade do solo (Ds). A umidade volumétrica ( $\theta$ ) foi obtida a partir da multiplicação da umidade gravimétrica pela densidade do solo, $\mathrm{em} \mathrm{kg} \mathrm{dm}^{-3}$.

$\mathrm{Na}$ fase intermediária de desenvolvimento das touceiras para a safra 2002/2003, a distribuição do sistema radicular foi avaliada a partir do método da trincheira ou parede do perfil. No NV foram abertas, manualmente, três trincheiras para cada um dos cultivares supramencionados, nas dimensões de $1,40 \times 1,50 \times 1,00 \mathrm{~m}$. No LVA, as trincheiras apresentaram as dimensões de $1,10 \times 1,50 \times 1,00 \mathrm{~m}$. A parede utilizada para estudo das raízes foi a transversal às linhas de cana, buscando-se verificar o efeito da passagem de máquinas nas entrelinhas da cultura (Figura 1).

Após abertura das trincheiras, as raízes expostas foram pintadas individualmente com tinta látex branca, com intuito de melhorar o contraste entre raízes e solo. Após pintura, foram obtidas imagens com câmera fotográfica digital.

A área de perfil analisada no NV foi de $1,40 \mathrm{~m}$ de largura, que corresponde ao espaçamento da cultura para esse solo $(0,70 \mathrm{~m}$ de cada lado), e $0,69 \mathrm{~m}$ de profundidade. No LVA, a área foi de 1,10 m de largura ( $0,55 \mathrm{~m}$ de cada lado), correspondente ao espaçamento da cultura nesse solo, e 0,72 $\mathrm{m}$ de profundidade. As imagens foram obtidas em quadrículas previamente identificadas e que apresentaram dimensões de $0,18 \times 0,18 \mathrm{~m}$ (total de 24 quadrículas por perfil) no LVA e de $0,23 \times 0,23 \mathrm{~m}$ (total de 18 quadrículas por perfil) no NV (Figura 1).

As variações nas distâncias horizontais e profundidades entre LVA e NV foram estabelecidas em função da diferença nas dimensões das quadrículas dos grids usados para avaliar a distribuição radicular no perfil dos solos. O tamanho das quadrículas variou com a diferença no espaçamento entre linhas de cana para cada solo estudado.

As imagens de raízes foram analisadas com o software SIARCS (Guimarães et al., 1997), obtendose valores de comprimento de raízes. Resultados de comprimento radicular provenientes de imagens obtidas a três distâncias entre parede do perfil e touceira de cana $(30,20$ e $10 \mathrm{~cm})$ foram somados, para reduzir efeitos da variabilidade nos procedimentos estatísticos.

As análises estatísticas de atributos químicos e físicos do solo, teor de nutrientes nas folhas, produtividade da cultura, atributos de qualidade do caldo e da distribuição de raízes no perfil do solo foram feitas 


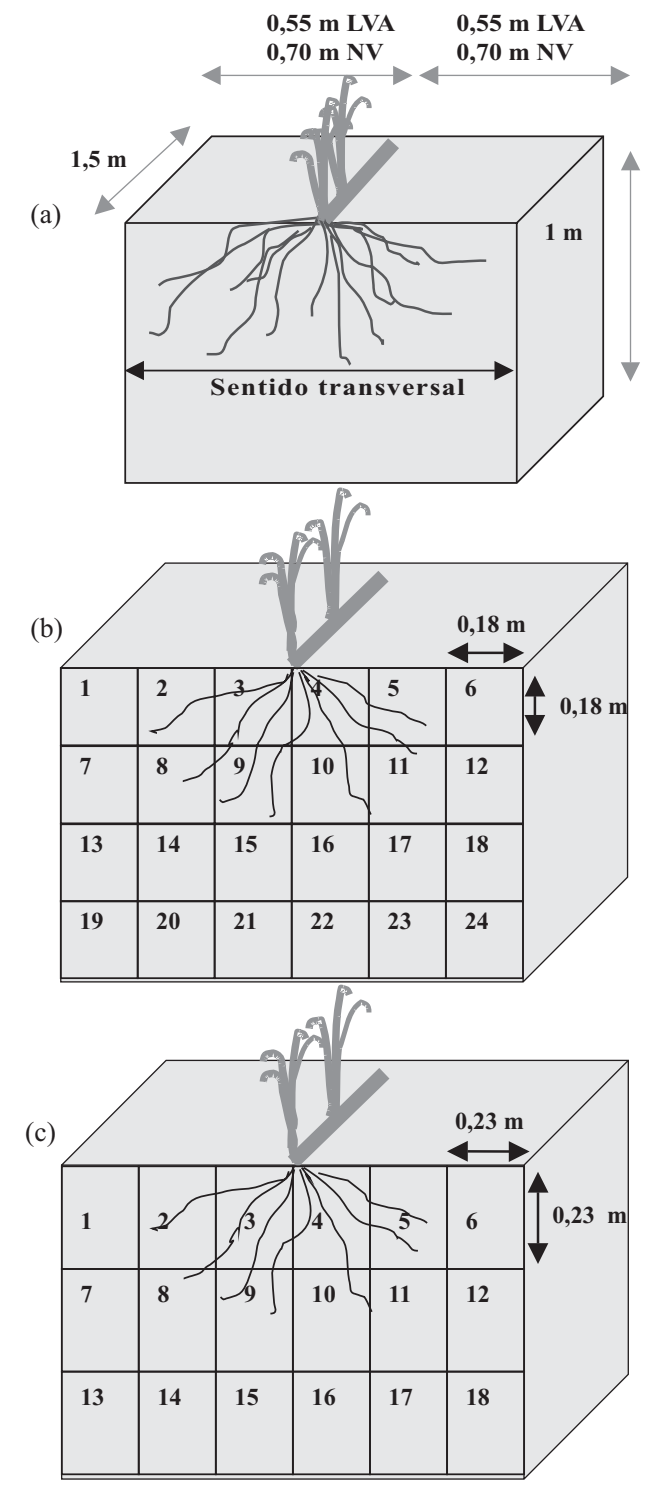

Figura 1. Esquema das trincheiras e da posição utilizada para avaliação do sistema radicular (a); número e dimensões das quadrículas em perfil no LVA (b); número e dimensões das quadrículas em perfil no $\mathrm{NV}$ (c).

com o programa Genstat versão 7.1 NAG. Ltda (Jackson, 2006). A análise de variância $(\alpha=0,05)$ foi conduzida utilizando o procedimento ANOVA para os delineamentos em blocos casualizados, parcelas subdivididas e parcelas subsubdivididas.

No delineamento em blocos casualizados, a comparação de médias foi feita a partir do teste de Tukey. Atributos analisados estatisticamente a partir do delineamento parcela subdividida e subsubdividida apresentaram separação de médias pelo procedimento da diferença mínima significativa (PSE-diff). No estudo da distribuição de raízes no perfil, contrastes ortogonais foram utilizados para verificar diferenças entre os dois lados das touceiras de cana-de-açúcar.

\section{RESULTADOS E DISCUSSÃO}

As principais diferenças quanto aos atributos químicos do solo ocorreram no $\mathrm{pH}$ e na acidez potencial $(\mathrm{H}+\mathrm{Al})$. Nas profundidades de $0-20$ e $20-40 \mathrm{~cm}$, valores de $\mathrm{pH}$ foram menores com o cultivar RB835089 no NV (Figura 2). A diferença de pH na profundidade de $0-20 \mathrm{~cm}$ foi refletida na acidez potencial, conforme já descrito por outros autores (Fernandes et al., 2002). A acidez potencial foi maior mediante menores valores de $\mathrm{pH}$.

No LVA, apesar da maior concentração de hidrogênio e maior acidez potencial para o cultivar RB83-5486 nas duas profundidades estudadas, não foi constatada diferença estatística. Provavelmente a ausência de resposta estatística ocorreu em função da maior variabilidade nos valores de $\mathrm{pH}$ e acidez potencial no LVA, que, por apresentar menor CTC, possui menor poder-tampão (Raij, 1991).

Fatores relacionados à planta e ao solo definem se a mudança no $\mathrm{pH}$ será verificada não só na rizosfera, mas também na solução do solo (Marschner \& Hömheld, 1996). Estudos mostraram que plantas acidificaram o solo a partir da liberação de prótons

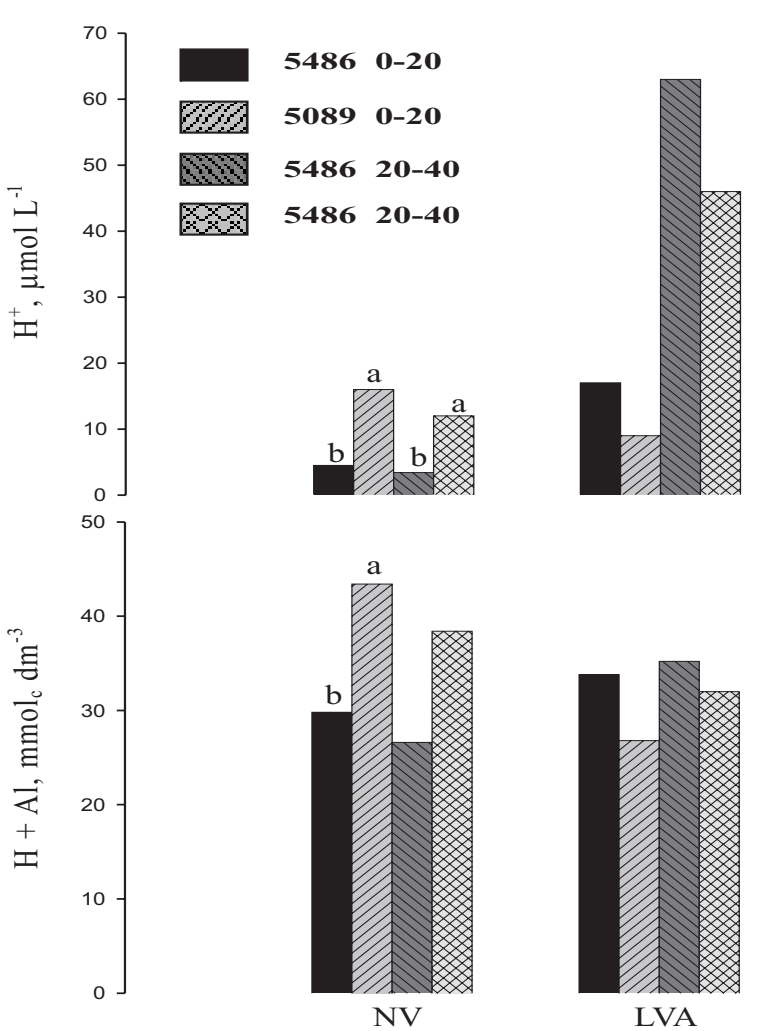

Figura 2. Concentração de íons $\mathrm{H}^{+}$e acidez potencial $(\mathrm{H}+\mathrm{Al})$ em duas profundidades dos solos $\mathrm{NV}$ e LVA com os cultivares de cana-de-açúcar RB835089 e RB83-5486 (amostras coletadas no final da safra 2001/2002). Letras diferentes dentro de cada profundidade indicam que médias diferem entre si pelo teste de Tukey a $5 \%$. 
pelo sistema radicular quando a absorção de cátions foi superior à de ânions (Tang \& Rengel, 2003).

Os menores valores de $\mathrm{pH}$ encontrados no $\mathrm{NV}$ com o RB83-5089 poderiam ser decorrentes da maior atividade radicular na absorção de nutrientes desse cultivar. Entretanto, não é possível afirmar que a absorção de nutrientes na forma catiônica prevaleceu sobre a forma aniônica.

Na figura 3 são apresentados teores de macronutrientes e micronutrientes no tecido foliar dos cultivares de cana-de-açúcar RB83-5486 e RB83-5089, coletado nas safras 2002/2003 e 2003/2004, nos solos LVA e NV.

Nos resultados referentes à safra 2002/2003, foi verificada diferença entre cultivares quanto ao teor foliar de macronutrientes nos dois solos, com exceção para teores de S no LVA e P no NV. O cultivar RB835486 mostrou maior teor foliar de potássio (K) nos dois solos, apresentando também tendência de maior teor de S. Já o cultivar RB83-5089 teve maior teor foliar de N, Ca e Mg; todavia, diferença no teor foliar de $\mathrm{P}$, com maior valor para RB83-5089, somente foi verificada no LVA.

Na safra 2003/2004 os resultados indicaram que, no LVA, o cultivar RB83-5089 apresentou maiores teores de N, P e Ca, e o RB83-5486, maior teor de S. No NV, o cultivar RB83-5089 apresentou maiores teores de N, Ca e Mg; já o RB83-5486 mostrou maior teor foliar de $\mathrm{S}$.

A diferenca no teor foliar de $\mathrm{P}$ entre cultivares foi menor no NV do que no LVA. A maior fixação do P no solo com teor de argila mais elevado (NV) resultou em
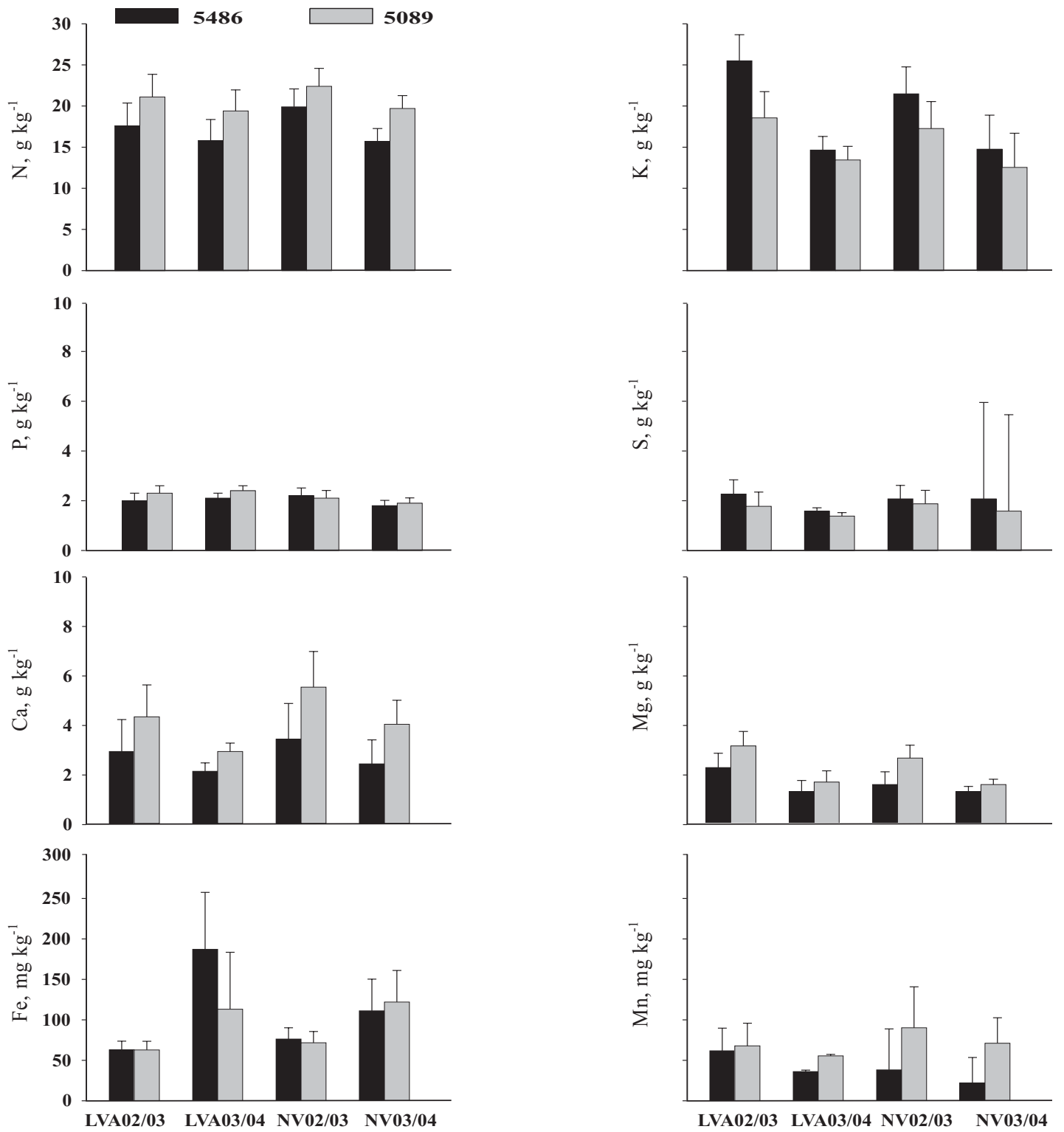

Figura 3. Teor foliar de macronutrientes e micronutrientes nas safras 2002/2003 e 2003/2004 para dois cultivares de cana-de-açúcar plantados nos solos LVA e NV. Diferença Mínima Significativa (DMS) a $5 \%$. 
menor disponibilidade do nutriente, contribuindo com o teor foliar semelhante entre os cultivares estudados. No LVA, em função do menor teor de argila, houve menor fixação de $\mathrm{P}$, que proporcionou maior disponibilidade do nutriente às plantas, resultando em diferença entre cultivares.

Comparando teores de nutrientes resultantes da análise do tecido foliar com os valores considerados adequados por Malavolta (1994) para a cultura da canade-açúcar, constatou-se teor elevado de potássio na safra 2002/2003, enquanto teores de cálcio e enxofre estiveram abaixo dos valores considerados adequados. Na safra 2003/2004, teores de potássio não foram tão elevados como na safra anterior.

A prévia aplicação de vinhaça nas áreas experimentais causou desbalanceamento na relação de bases trocáveis ( $\mathrm{Ca}: \mathrm{Mg}: \mathrm{K}$ ), aumentando a disponibilidade de $\mathrm{K}$ em relação às outras bases. $\mathrm{A}$ elevada absorção de K prejudicou a absorção de Ca e $\mathrm{Mg}$, o que pode ser confirmado pelo maior teor foliar de $\mathrm{K}$ e menores teores de $\mathrm{Ca}$ e $\mathrm{Mg}$ para o cultivar RB83-5486. Considerando a última safra (2001/2002), em que ocorreu aplicação de vinhaça, houve maior efeito residual na safra 2002/2003 do que na safra 2003/ 2004.

Na safra 2002/2003 foi encontrado maior teor de K nas folhas do cultivar RB83-5486. Caso esse teor foliar de $\mathrm{K}$ tivesse refletido em maior extração do elemento por colmos na referida safra, seriam confirmados os resultados de Coleti et al. (2002), em que o cultivar, quando comparado com o SP81-3250, apresentou maior extração desse macronutriente, justificando sua elevada aptidão industrial para produção de álcool.

Teores adequados de potássio aumentam a sacarose na cana-de-açúcar (Hauck \& Dickinson, 1954). Por sua vez, a maior absorção de potássio pela planta aumenta o teor de cinzas do caldo. O maior teor de cinzas dificulta o processo de cristalização, sendo um efeito negativo na fabricação de açúcar. Todavia, os constituintes das cinzas do caldo agem como fonte de nutrientes para o processo fermentativo, aumentando a velocidade de desdobramento dos açúcares em álcool, o que favorece a fabricação de etanol.

$\mathrm{Na}$ figura 4, verifica-se o diferencial de água armazenada entre os dois solos. A figura também ilustra a diferença ocorrida na retenção de água para as profundidades avaliadas. A retenção de água foi maior no NV, que também apresentou diferença na retenção entre profundidades. A partir da tensão de $1 \mathrm{kPa}$, a retenção de água no NV foi menor nos primeiros $20 \mathrm{~cm}$ de profundidade.

No NV, a profundidade $20-40 \mathrm{~cm}$ caracterizou a camada de impedimento físico, apresentando maiores valores de densidade do solo e resistência à penetração. $\mathrm{Na}$ mesma camada foram encontradas menores

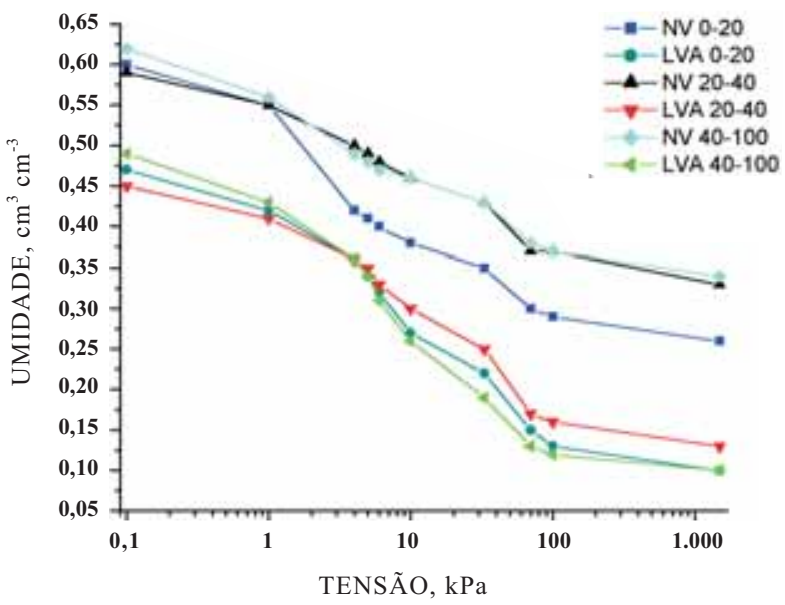

Figura 4. Curva de retenção de água para três profundidades dos solos NV e LVA.

percentagens de porosidade total e de macroporos, como resultado da compactação (Quadro 3). A menor retenção de água a partir da tensão de $1 \mathrm{kPa}$, na profundidade $0-20 \mathrm{~cm}$ no NV, pode ser explicada pela maior percentagem de macroporos nessa camada (quando comparada às demais camadas), que proporcionou a drenagem da água.

Conforme os valores de densidade do solo mencionados por Veihmeyer \& Hendrickson (1949) como restritivos ao crescimento de raízes de várias espécies de plantas, o solo argiloso apresentou densidade desfavorável ao crescimento radicular nas três profundidades estudadas. Já no LVA, a densidade do solo não figurou como restritiva às raízes. Entretanto, Humbert (1974), sem especificar a textura do solo, menciona que a densidade de $1,36 \mathrm{~g} \mathrm{~cm}^{-3}$ comprometeu o crescimento de raízes de cana-deaçúcar.

A relação entre resistência à penetração e crescimento radicular foi estudada por vários autores (Boone et al., 1986; Rosolem et al., 2002), e os valores considerados restritivos ao crescimento radicular variaram de 1,34 a $3 \mathrm{MPa}$ para diferentes espécies. Pfeffer $(1983)^{(6)}$, citado por Bennie (1996), fez as primeiras medidas diretas da máxima pressão de crescimento radicular, encontrando valores entre 0,7 e 2,5 MPa para diferentes espécies.

$\mathrm{Na}$ avaliação da distribuição radicular, o comprimento de raízes medido no perfil do solo indicou que, nos primeiros $18 \mathrm{~cm}$ de profundidade do LVA, o lado direito das linhas de cana apresentou maior comprimento de raízes. O cultivar RB83-5486 mostrou maior comprimento de raízes que RB83-5089 nas três distâncias horizontais. O maior comprimento de raízes ocorreu na distância horizontal de $0-18 \mathrm{~cm}$ para os dois cultivares (Figura 5).

${ }^{(6)}$ PFEFFER, W. Druck und Arbeitsleistung durch wachsende Pflanzen. Abhandlungen der Sächsischen Akademie der Wissenschaften zu Leipzig. v. 33, p. 235-474, 1893. 
Na profundidade de $18-36 \mathrm{~cm}$, o cultivar RB835486 teve maior comprimento radicular que RB835089 , principalmente do lado direito das touceiras de cana. Do lado esquerdo houve diferença entre cultivares somente na distância horizontal de 36-54 cm. Maior comprimento radicular ocorreu na distância horizontal de 0-18 cm para o RB83-5486, enquanto o RB83-5089 apresentou distribuição horizontal homogênea nessa profundidade (Figura 5).
A partir dos 36 até $54 \mathrm{~cm}$ de profundidade, o RB835486 apresentou maior comprimento radicular que RB83-5089 nas três distâncias horizontais do lado direito e somente na distância horizontal de $0-18 \mathrm{~cm}$ do lado esquerdo das linhas de cana (Figura 5).

Diferença entre RB83-5486 e RB83-5089 foi encontrada para comprimento radicular na profundidade de 54-72 cm no LVA, sobretudo do lado direito das linhas de cana. Na distribuição horizontal,

\section{Quadro 3. Média de atributos físicos entre profundidades para os solos LVA e NV}

\begin{tabular}{|c|c|c|c|c|c|}
\hline Profundidade & Ds & $\mathbf{R P}$ & Ptotal & Macroporos & Microporos \\
\hline $\mathrm{cm}$ & $\mathrm{kg} \mathrm{dm} \mathrm{m}^{-3}$ & $\mathrm{MPa}$ & 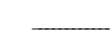 & $\%$ & $\underline{-}$ \\
\hline \multicolumn{6}{|c|}{ Latossolo Vermelho-Amarelo distrófico psamítico (LVA) } \\
\hline $0-20$ & 1,53 & $1,24 \mathrm{a}$ & 47 & 11 & 36 \\
\hline $20-40$ & 1,58 & $0,44 \mathrm{~b}$ & 44 & 10 & 34 \\
\hline $40-100$ & 1,52 & $0,22 \mathrm{~b}$ & 47 & 14 & 33 \\
\hline \multicolumn{6}{|c|}{ Nitossolo Vermelho eutroférrico latossólico (NV) } \\
\hline $0-20$ & $1,47 \mathrm{~b}$ & $0,91 \mathrm{c}$ & $49 \mathrm{a}$ & $18 \mathrm{a}$ & 31 \\
\hline $20-40$ & $1,77 \mathrm{a}$ & $2,52 \mathrm{a}$ & $44 \mathrm{~b}$ & $9 \mathrm{~b}$ & 35 \\
\hline $40-100$ & $1,49 \mathrm{~b}$ & $1,57 \mathrm{~b}$ & $50 \mathrm{a}$ & $13 \mathrm{ab}$ & 37 \\
\hline
\end{tabular}

Ds: densidade do solo, RP: resistência à penetração, Ptotal: porosidade total. Médias de três repetições contidas em colunas e seguidas de mesma letra não diferem entre si pela diferença mínima significativa (DMS) a $5 \%$.
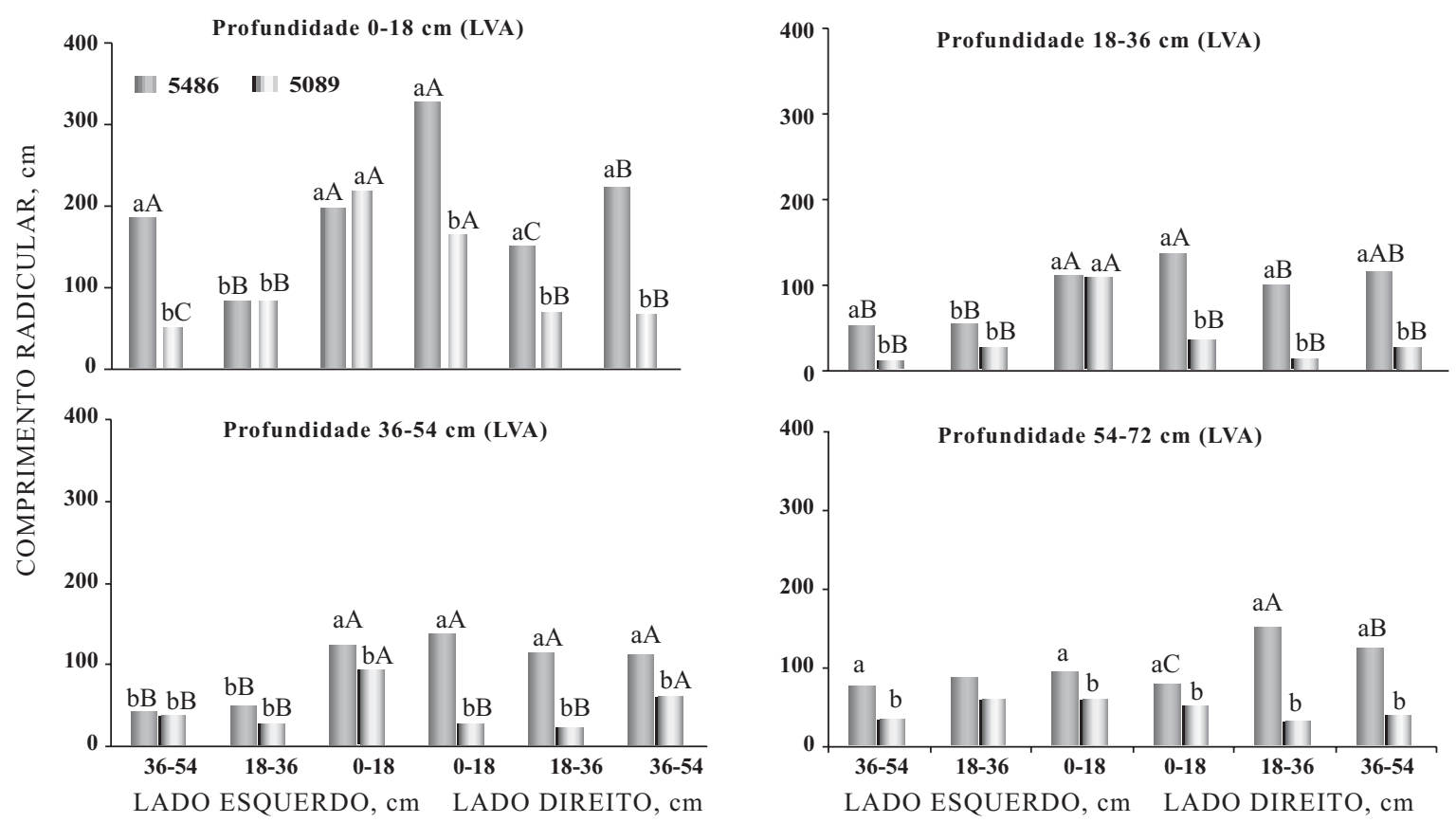

Figura 5. Comprimento radicular nos lados esquerdo e direito das linhas de cana-de-açúcar em quatro profundidades no LVA. Letras minúsculas comparam cultivares dentro de cada distância horizontal. Letras maiúsculas comparam cada cultivar em relação às três distâncias horizontais. Diferença mínima significativa (DMS) a $5 \%$. 
RB83-5486 apresentou maior diferença, com maior valor de comprimento radicular na distância de 18$36 \mathrm{~cm}$ da linha (Figura 5).

Quanto à distribuição horizontal no NV, nos primeiros $23 \mathrm{~cm}$ de profundidade foi constatado maior comprimento radicular para o cultivar RB83-5486, nos dois lados das linhas de cana. O maior comprimento de raízes foi encontrado na distância de $0-23 \mathrm{~cm}$ das linhas, principalmente para o RB83-5486. Já o cultivar RB83-5089 mostrou distribuição horizontal homogênea (Figura 6).

A partir dos $23 \mathrm{~cm}$ de profundidade, a diferença entre cultivares foi verificada principalmente do lado esquerdo das linhas. Maiores valores de comprimento radicular ocorreram nas distâncias de 0-23 e 23-46 cm das linhas de cana nos dois cultivares. Na profundidade de 46-69 cm somente houve diferença entre cultivares na distância de 46-69 cm, do lado direito das linhas de cana (Figura 6).

Faroni (2005) encontrou $65 \%$ da quantidade de raízes de cana-de-açúcar na projeção das linhas e somente $18 \%$ na distância de $14 \mathrm{a} 42 \mathrm{~cm}$. Alvarez

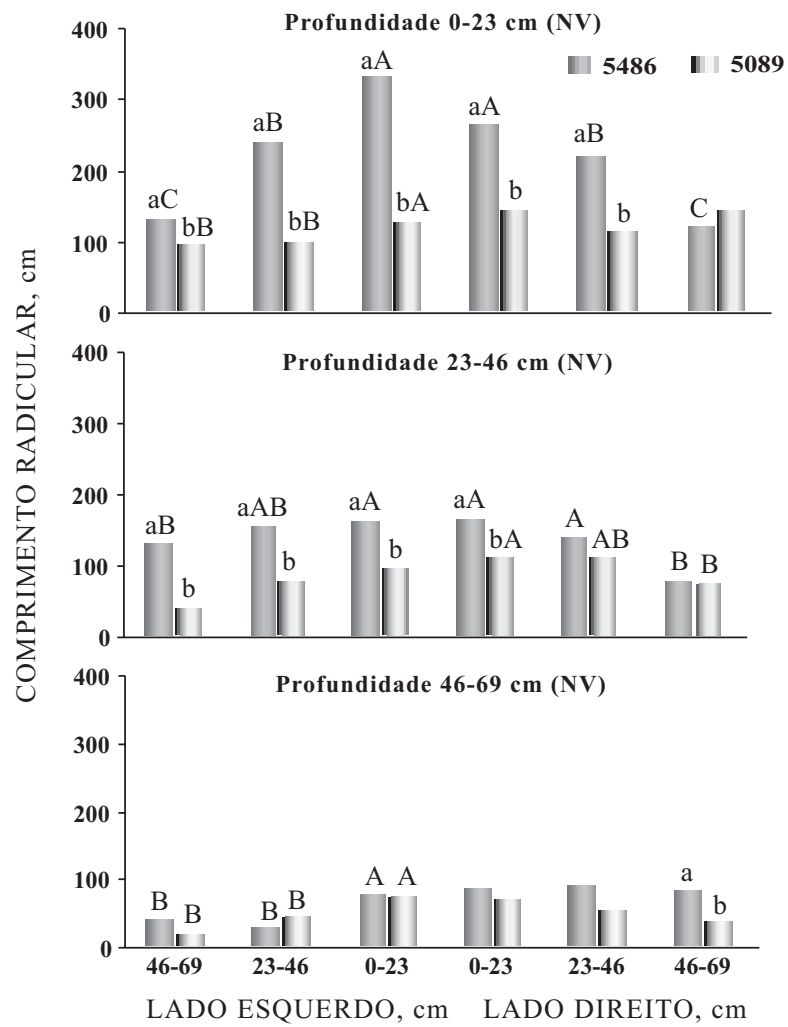

Figura 6. Comprimento radicular nos lados esquerdo e direito das linhas de cana-de-açúcar em três profundidades no NV. Letras minúsculas comparam cultivares dentro de cada distância horizontal. Letras maiúsculas comparam cada cultivar em relação às três distâncias horizontais. Diferença Mínima Significativa (DMS) a $5 \%$.
(2000) também observou maior quantidade de raízes bem próxima às linhas de cana.

A distribuição horizontal de raízes de cana-de-açúcar pode ser influenciada pela posição em que é aplicada a adubação de soqueiras e pelo efeito do tráfego de máquinas e implementos. O acúmulo de nutrientes em determinado local no solo pode proporcionar maior crescimento de raízes, devido à maior disponibilidade de nutrientes (Dunbabin et al., 2001). O efeito do tráfego de máquinas e implementos pode ocasionar maior compactação em locais específicos, que apresentarão condições desfavoráveis ao desenvolvimento radicular. Como o tráfego ocorre principalmente nas entrelinhas, maior compactação e menor quantidade de raízes são esperadas nesse local. Trabalhos mostraram efeitos do tráfego de máquinas nas linhas de cana (Vasconcelos, 2002; Faroni, 2005).

$\mathrm{Na}$ avaliação da distribuição radicular vertical no LVA, o cultivar RB83-5486 diferiu do RB83-5089 no lado direito das linhas de cana-de-açúcar, apresentando maior comprimento radicular em todas as profundidades. Os primeiros $18 \mathrm{~cm}$ de profundidade mostraram maior comprimento de raízes. A redução no comprimento radicular foi acentuada quando se passou da profundidade de 0-18 para 18-36 cm. Já nas maiores profundidades, a redução no comprimento radicular não foi acentuada (Figura 7).

No NV, o cultivar RB83-5486 somente diferiu do RB83-5089 nos primeiros $23 \mathrm{~cm}$ de profundidade do lado direito. Do lado esquerdo, os cultivares diferiram nas profundidades de 0-23 e $23-46 \mathrm{~cm}$. Nas camadas mais profundas, a redução no comprimento radicular foi mais acentuada, exibindo menores valores em relação àqueles encontrados no LVA, sobretudo para o cultivar RB83-5486 (Figura 8).

No LVA, o maior comprimento radicular do RB835486 em relação ao $\mathrm{RB} 83-5089$, associado à melhor distribuição de raízes em profundidade, constituiu característica favorável do cultivar RB83-5486. Maior quantidade de raízes em profundidade, além de favorecer a absorção de água em épocas de déficit hídrico, permite a absorção de nitrogênio que tenha sido deslocado para camadas mais profundas (Gregory et al., 1979).

Outros estudos referentes à distribuição vertical de raízes de cana-de-açúcar no perfil do solo indicaram cerca de 60 a $70 \%$ da quantidade de raízes concentrando-se nos primeiros $20 \mathrm{~cm}$ de profundidade (Alvarez, 2000; Faroni, 2005).

Vasconcelos (2002) menciona que a quantidade e a distribuição de raízes de cana-de-açúcar mudam ao longo do tempo, devido às alterações naturais no clima e no solo e à ação antrópica. Esse autor encontrou diferença entre cultivares quanto à distribuição de raízes em profundidade no perfil do solo, afirmando que a maior quantidade de raízes em camadas mais profundas é atribuída à tolerância ao alumínio existente em determinados cultivares. 
Com relação à produção de colmos e açúcar, a terceira e quarta socas apresentaram maiores valores do que a quinta soca para os dois cultivares no LVA. Já no
NV, a produção de colmos foi maior para RB83-5089 nos três cortes, enquanto a produção de açúcar foi maior para RB83-5486 na terceira e quarta socas (Quadro 4).

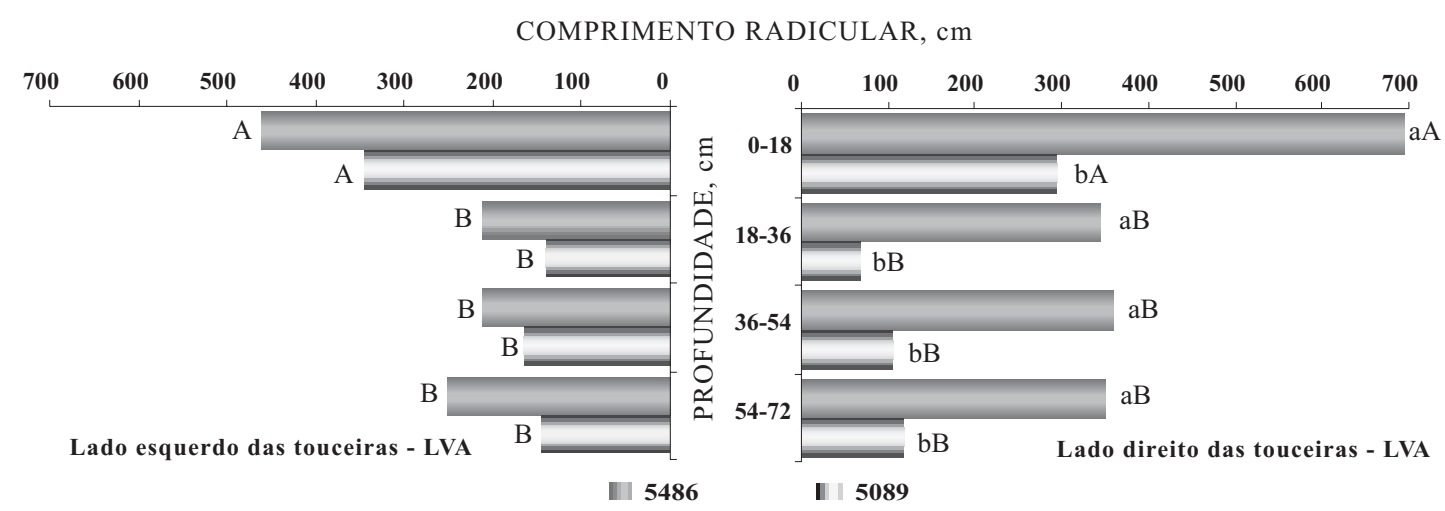

Figura 7. Comprimento radicular de soqueiras de cana-de-açúcar em profundidade no perfil do LVA. Letras minúsculas comparam cultivares dentro de cada profundidade. Letras maiúsculas comparam cada cultivar em relação às quatro profundidades pela Diferença Mínima Significativa (DMS) a $5 \%$.

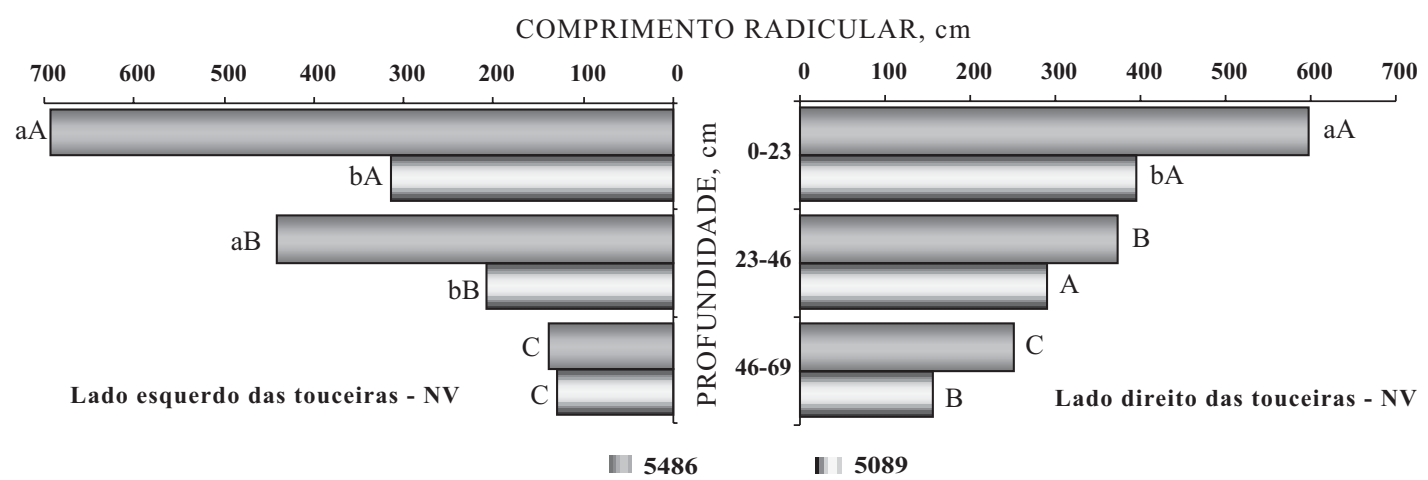

Figura 8. Comprimento radicular de soqueiras de cana-de-açúcar em profundidade no perfil do NV. Letras minúsculas comparam cultivares dentro de cada profundidade. Letras maiúsculas comparam cada cultivar em relação às três profundidades pela Diferença Mínima Significativa (DMS) a $5 \%$.

Quadro 4. Produção de colmos e de açúcar em três safras para os cultivares RB83-5089 e RB83-5486, plantados em dois solos

\begin{tabular}{|c|c|c|c|c|c|c|}
\hline \multirow{2}{*}{ Variedade } & \multicolumn{3}{|c|}{ Produção de colmo } & \multicolumn{3}{|c|}{ Produção de açúcar } \\
\hline & $2001 / 02$ & $2002 / 03$ & $2003 / 04$ & $2001 / 02$ & $2002 / 03$ & $2003 / 04$ \\
\hline & & & & & & \\
\hline RB83-5486 & $96 \mathrm{~b}$ & $118 \mathrm{~b}$ & 65 & $18 \mathrm{a}$ & 16 & $16 \mathrm{a}$ \\
\hline RB83-5089 & $112 \mathrm{a}$ & $142 \mathrm{a}$ & 72 & $17 \mathrm{~b}$ & 16 & $15 \mathrm{~b}$ \\
\hline \multirow[t]{2}{*}{ DMS } & 12 & 20 & 19 & 0,9 & 0,8 & 0,9 \\
\hline & & & & & & \\
\hline RB83-5486 & $96 \mathrm{~b}$ & $114 \mathrm{~b}$ & $82 \mathrm{~b}$ & $16 \mathrm{a}$ & $16 \mathrm{a}$ & $10 \mathrm{~b}$ \\
\hline RB83-5089 & $122 \mathrm{a}$ & $135 \mathrm{a}$ & $106 \mathrm{a}$ & $15 \mathrm{~b}$ & $15 \mathrm{~b}$ & $12 \mathrm{a}$ \\
\hline DMS & 8 & 12 & 10 & 0,8 & 0,9 & 1,8 \\
\hline
\end{tabular}


A elevada produção de colmos encontrada para RB83-5089 indica que esse cultivar foi mais vigoroso tanto em solo arenoso quanto no argiloso. Entretanto, essas características não se traduziram necessariamente em elevado potencial de produção de açúcar, confirmando relatos de que o cultivar RB835089, alta produção de colmos e o RB83-5486, elevada produção de açúcar (Gomes, 2003). O grande potencial de produção de açúcar do cultivar RB83-5486 foi descrito como característica genotípica (PMGCA, 2005), e esse cultivar apresentou alta produção de açúcar em solo com maior ou menor potencial produtivo.

\section{CONCLUSÕES}

1. O cultivar RB83-5486 apresenta melhor distribuição de raízes em solo com menor teor de argila devido à redução menos acentuada do comprimento radicular em profundidade.

2. Quando comparado com um cultivar que apresenta distribuição radicular mais uniforme em perfil de solo com maior teor de argila, o RB83-5486 é mais suscetível à redução na produção de colmos, principalmente em anos com baixa precipitação ou com distribuição de chuvas insatisfatória. Como conseqüência, o potencial produtivo do cultivar pode ser comprometido, ficando a produção de açúcar abaixo da esperada.

\section{AGRADECIMENTOS}

À Professora Dra. Maria de Fátima Guimarães (CCA/UEL), pelos esclarecimentos metodológicos. À CAPES e à FAPESP, pelo suporte financeiro. Ao Departamento de Solos e Nutrição de Plantas da ESALQ/USP e ao grupo COSAN, pela infra-estrutura de trabalho.

\section{LITERATURA CITADA}

ABREU, C.A.; ABREU, M.F. \& ANDRADE, J.C. Determinação de cobre, ferro, manganês, zinco, cádmio, cromo, níquel e chumbo em solos usando a solução DTPA em pH 7,3. In: RAIJ, B.van; ANDRADE, J.C.; CANTARELLA, H. \& QUAGGIO, J.A., eds. Análise química para avaliação da fertilidade de solos tropicais. Campinas, Instituto Agronômico, 2001b. p.240-250.

ABREU, M.F.; ABREU, C.A. \& ANDRADE, J.C. Determinação de boro em água quente, usando aquecimento com microonda. In: RAIJ, B. van; ANDRADE, J.C.; CANTARELlA, H. \& QUAGGIO, J.A., eds. Análise química para avaliação da fertilidade de solos tropicais. Campinas, Instituto Agronômico, 2001a. p. 231-239.
ALVAREZ, I.A.; CASTRO, P.R.C. \& NOGUEIRA, M.C.S. Crescimento de raízes de cana crua e queimada em dois ciclos. Sci. Agríc., 57:653-659, 2000.

AVILAN R., L.R. Estudio del sistema radicular de la cana de azucar variedad V58-4 en un mollisol del estado Portuguesa. Agron. Trop., 28:163-174, 1978.

AVILAN, L.R.; GRANADOS F.M. \& ORTEGA, D. Estudio del sistema radicular de tres variedades de caña de azúcar (Saccharum spp.) en un Mollisol de los Valles de Aragua. Agron. Trop., 27:69-87, 1977.

BENNIE, A.T.P. Growth and mechanical impedance. In: WAISEL, Y.; ESHEL, A. \& KAFKAFI, U., eds. Plant roots: The hidden half. New York, Marcel Dekker, 1996. p.453470 .

BOONE, F.R.; van der WERF, H.M.G.; KROESBERGEN, B.; TEN HAG, B.A. \& BOERS, A. The effect of compaction of the arable layer in sandy soil on the growth of maize for silage. 1 Critical matric water potentials in relation to soil aeration and mechanical impedance. Nether. J. Agric. Sci., 34:155-171, 1986.

COLETI, J.T.; STUPIELLO, J.J.; OLIVEIRA, G.R.D.; CASAGRANDE, J. C. \& RIBEIRO, L.D. Remoção de macronutrientes pela cana-planta e cana-soca em Argissolos, variedades RB 835486 e SP 813250. In: CONGRESSO NACIONAL DA SOCIEDADE DOS TÉCNICOS AÇUCAREIROS E ALCOOLEIROS DO BRASIL, 8., Recife, 2002. Anais. Recife, STAB, 2002. p.316321.

DIAS, F.L.F. Relação entre produtividade, clima, solos e variedades de cana-de-açúcar, na região noroeste do Estado de São Paulo. Piracicaba, Escola Superior de Agricultura Luiz de Queiroz, 1997. 61p. (Tese de Mestrado)

DUNBABIN, V.; RENGEL, Z. \& DIGGLE, A. The root growth response to heterogeneous nitrate supply differs for Lupinus angustifolius and Lupinus pilosus. Austr. J. Agric. Res.,52:495-503, 2001.

EMPRESA BRASILEIRA DE PESQUISA AGROPECUÁRIA EMBRAPA. Centro Nacional de Pesquisa de Solos. Sistema brasileiro de classificação de solos. Rio de Janeiro, 1999. 412p.

FARONI, C.E. Sistema radicular de cana-de-açúcar e identificação de raízes metabolicamente ativas. Piracicaba, Escola Superior de Agricultura Luiz de Queiroz, 2005. 68p. (Tese de Mestrado)

FERNANDES, J. Observações sobre o sistema radicular da cana-de-açúcar. Álcool \& Açúcar, 5:51-52, 1985.

FERNANDES, S.A.P.; BERNOUX, M.; CERRI, C.C.; FEIGL, B.J. \& PICCOLO, M. Seasonal variation of soil chemical properties and $\mathrm{CO}_{2}$ and $\mathrm{CH}_{4}$ fluxes in unfertilized and $\mathrm{P}$ fertilized pastures in an Ultisol of the Brazilian Amazon. Geoderma, 107:227-241, 2002.

GALLO, J.R. Amostragem em cana-de-açúcar para fins de análise foliar. Bragantia, 21:899-921, 1962.

GEE, G.W. \& BAUDER, J.W. Particle-size analysis. In: KLUTE, A., ed. Methods of soil analysis: Physical and mineralogical methods. 2.ed. Madison, American Society of Agronomy, 1986. p.383-409. 
GOMES, J.F.F. Produção de colmos e exportação de macronutrientes primários por cultivares de cana-deaçúcar (Saccharum spp.). Piracicaba, Escola Superior de Agricultura Luiz de Queiroz, 2003. 65p. (Tese de Mestrado)

GREGORY, C.J.; CRAWFOR, D.V. \& MCGOWAN, M. Nutrient relations of winter wheat. II Movement of nutrients to the root and their uptake. J. Agric. Sci., 93:495-504, 1979.

GUIMARÃES, M.F.; JORGE, L.A.C.; DE MARIA, I.C.; TAVARES FILHO, J.; BICUDO, S.J. \& CRESTANA, S. Três metodologias de avaliação de raízes: Descrição, limitações e vantagens. In: SIMPÓSIO NACIONAL DE INSTRUMENTAÇÃO AGROPECUÁRIA - SIAGRO, 1. São Carlos, 1996. Anais. São Carlos, Embrapa/CNPDIA, 1997. p.295-304.

HAUCK, F.W. \& DICKINSON, J. Conveniência y experimentacion con potasio en el cultivo de caña de azucar. ATAC - R. Técnica Inf., 13:626-635, 1954.

HUMBERT, R.P. El cultivo de la caña de azucar. México, Continental, 1974. 719p.

JACKSON, T. Biomathematics and statistics Scotland, Basic statistics in GENSTAT. http://www.bios.sari.ac.uk/smart/ unix/mbasgen/slides/frames.htm (24 ago.2006).

MALAVOLTA, E. Fertilizing for high yield sugarcane. Basel, IPI, 1994. 104p. (Bulletin, 14).

MALAVOLTA, E.; VITTI, G.C. \& OLIVEIRA, S.A. Avaliação do estado nutricional das plantas: Princípios e aplicações. 2.ed. Piracicaba, POTAFOS, 1997. 319p.

MARSCHNER, H. \& RÖMHELD, V. Root-induced changes in the availability of micronutrients in the rhizosphere. In WAISEL, Y.; ESHEL, A. \& KAFKAFI, U., eds. Plant roots: The hidden half. New York, Marcel Dekker, 1996. p.557579 .
MAULE, R.F.; MAZZA, J.A. \& MARTHA JÚNIOR, G.B. Produtividade agrícola de cultivares de cana-de-açúcar em diferentes solos e épocas de colheita. Sci. Agríc., 58:295$301,2001$.

PROGRAMA DE MELHORAMENTO GENÉTICO DA CANADE-AÇÚCAR - PMGCA. Catálogo de variedades. Disponível em: (http://pmgca.dbv.cca.ufscar.br/htm/catal/ catvaried.php) Acesso em 20 jun. de 2005).

RAIJ, B. van; QUAGGIO, J.A.; CANTARELLA, H.; FERREIRA, M.E.; LOPES, A.S. \& BATAGLIA, O.C. Análise química do solo para fins de fertilidade. Campinas, Fundação Cargill, 2001. 170p.

RAIJ, B.van. Fertilidade do solo e adubação. Piracicaba, Agronômica Ceres, 1991. 343p.

ROSOLEM, C.A.; FOLONI, J.S.S. \& TIRITAN, C.S. Root growth and nutrient accumulation in cover crops as affected by soil compaction. Soil Till. Res., 65:109-115, 2002.

TANG, C. \& RENGEL, Z. Role of plant cation/anion uptake ratio in soil acidification. In: RENGEL, Z., ed. Handbook of soil acidity. New York, Marcel Dekker, 2003. p.57-81.

VASCONCELOS, A.C.M. Desenvolvimento do sistema radicular e da parte aérea de socas de cana-de-açúcar sob dois sistemas de colheita: Crua mecanizada e queimada manual. Jaboticabal, Universidade Estadual Paulista Júlio de Mesquita Filho, 2002. 140p. (Tese de Doutorado)

VEIHMEYER, F.J. \& HENDRICKSON, A.H. Methods of measuring field capacity and wilting percentages of soils. Soil Sci., 68:75-94, 1949.

VITTI, G.C. Avaliação e interpretação do enxofre no solo e na planta. Jaboticabal, FUNEP, 1988. 37p. 